\title{
PARA NÃO DEIXAR DE DISCUTIR DE ONDE VEM, COMO ESTÁ E POR QUAL CAMINHO PODERÁ IR O ENSINO DE GEOGRAFIA: DA DISCIPLINARIDADE À INTERDISICPLINARIDADE
}

\author{
Apresentação: Comunicação Oral
}

Ângela Kerley Pereira Lima ${ }^{1}$

\begin{abstract}
Resumo
$\mathrm{O}$ artigo tem como objetivo central discutir o ensino de Geografia e suas implicações no aprendizado geográfico. Acredita-se que a Geografia, não somente enquanto ciência, mas, sobretudo, como disciplina, é capaz de formar cidadãos críticos e conscientes do seu papel de ser um sujeito ativo geográfico. Dessa forma, buscou-se entender a rede de complexidade entre a teoria e prática no ensino de Geografia e apresentar a interdisciplinaridade como meio de contribuição, ampliação e fortalecimento à compreensão não somente do professor, mas, sobretudo, do aluno. A pesquisa é do tipo qualitativa e utilizou o método revisão bibliográfica, pois pretendeu-se abordar na avaliação dos resultados a análise do discurso. Diante de sua conclusão se compreendeu os impasses contemporâneos do ensino de Geografia como uma extensão das raízes epistemológicas desde o reconhecimento enquanto ciência, portanto, influenciando nas práticas e tendências pedagógicas. Por outro lado, a interdisciplinaridade surge como uma prática ampliadora da realidade vivenciada, principalmente, por alunos, e isto traz novas possibilidades didáticas para o ensino e aprendizagem em Geografia.
\end{abstract}

Palavras-Chave: Ensino de Geografia. Práticas pedagógicas. Interdisplinaridade.

\section{Introdução}

Apesar da Geografia no século XXI ter incorporado as ações humanas como um elemento promotor do espaço geográfico e, sobretudo, a perspectiva de admitir, no caso da Geografia Critica, que o espaço é produto das manifestações sociais, pois, a sociedade é quem o produz e o reproduz. A Geografia escolar continuou a reproduzir uma Geografia desinteressante provavelmente por abordar conteúdos que não fossem atrativos, contextuais e atuais à realidade do aluno, ou, em outras palavras, insistindo nas práticas da Geografia tradicional. Neste caso, levanta-se a seguinte indagação: tais práticas seriam um problema metodológico atestado na didática do professor de Geografia? Certamente os obstáculos metodológicos da Geografia enquanto disciplina é um mosaico do processo científico, da percepção científica construída pelo professor e da forma da qual essa é praticada.

O grande desafio da Geografia enquanto disciplina escolar centraliza-se nos seguintes questionamentos: 1. Como levar os alunos a compreender a complexibilidade espacial do seu

\footnotetext{
${ }^{1}$ Licenciada em Geografia pela Universidade Regional do Cariri-URCA; Mestre em Desenvolvimento Regional Sustentável pela Universidade Federal do Cariri-UFCA; Professora substituta do IF Sertão Pernambucano e do curso de licenciatura em Geografia da FACHUSC; angelalimaufc@gmail.com.
} 
espaço vivido? 2. Qual a melhor forma de conduzir o aluno a refletir o espaço por meio das categorias de análise geográfica? 3. Quais os caminhos que levem o aluno a observar, analisar e produzir suas reflexões acerca das formas de ordenação espacial, das relações de poder, do direito à moradia e a saúde, da importância de conservar a paisagem cultural, da localização e orientação geográfica e dos impactos ambientais? Todas estas entre tantas outras. Enfim, problematizar estes fenômenos a partir do recorte espacial do seu local associando-o com o global.

Outros questionamentos se fazem pertinentes: 4. Como provocar os alunos a formularem questões sobre suas ações diretas no espaço? E, diante do processo das práticas de ensino, o mais desafiador para o professor do ensino de Geografia: 5. Quais os recursos que os professores de Geografia poderão utilizar para estimular e provocar a aprendizagem, proporcionar um ambiente cognitivo, interativo e interdisciplinar no processo de ensino, conduzir os alunos a identificar os fenômenos espaciais, bem como, produzir/utilizar materiais didáticos que fortaleçam, recriem e estimulem sua própria didática? Esta última indagação merece ênfase reflexiva, pois representa uma das fases e meios mais complexos do ato de ensinar.

Para Castrogiovanni (2007) se por um lado a Geografia enquanto ciência e disciplina é um instrumento de reflexão diante das ações humanas em todas as dimensões possíveis, é necessário, principalmente, no papel de professor(a) desta ciência, repensá-la em todos os atos processuais de sua prática, ensino e aprendizagem, pois,

“[...] a linguagem geográfica apresenta características que precisam ser consideradas, tanto quanto possível, como fonte de explicação para as dificuldades que os alunos possam vir a ter na sua compreensão, como para planejar movimentos pedagógicos que facilitem o processo interativo". (CASTROGIOVANNI, 2007, p.42).

$\mathrm{O}$ ato de reflexão continuo, também, leva o professor-educador-geógrafo a perceber o aluno como um sujeito que "traz consigo uma carga de experiência e de conhecimentos sistematizados ou não, realidades vividas e muitas vezes impossíveis de serem representadas pelos professores" (ibidem), um currículo oculto que traduz as particularidades do espaço vivido do aluno.

Tais colocações não são apenas um desafio entre o professor e o aluno, mas, do ensino e da escola, pois, enquanto um é o processo construído diante da própria cultura educacional associado as práticas, uso de metodologias e formulações de didáticas, o outro, é o espaço socialmente construído onde ocorrem todas as manifestações e materializações do processo educacional.

Outro ponto fundamental dentro do processo de ensino, do qual não se pode deixar de apresentar são as ações interdisciplinares. As ações na sua própria essência de prática estabelecem interconexões entre partes, o que pode considerar como uma tessitura de saberes e laços de 
interconexão entre partes e o todo (MORIN, 2009). A Geografia é a ciência que mais pode estabelecer diálogos com outras áreas de conhecimento tanto por abordar características físicas como sociais e culturais. "A Geografia talvez seja a disciplina que mais trabalhe com práticas interdisciplinares, percorrendo um leque de possibilidades na área de educação" (CASTROGIOVANNI, 2007, p.44).

Desta maneira, buscou, principalmente, em autores com teorias acerca do ensino de Geografia, analisar os discursos relacionados ao ensino de Geografia e suas implicações no aprendizado geográfico. E sistematizou-se em entender a rede de complexidade entre a teoria e prática no ensino de Geografia e apresentar a interdisciplinaridade como meio de contribuição, ampliação e fortalecimento à compreensão não somente do professor, mas, sobretudo, do aluno. A interdisciplinaridade é uma contribuição essencial para o aluno observador, pois agrega no seu processo de aprendizagem associações do mundo real. Para este objetivo central utilizou-se do método bibliográfico e para avaliação dos resultados analise do discurso.

\section{Fundamentação Teórica}

Discutir práticas de ensino e aprendizagem na disciplina de Geografia fortalecidas com propostas interdisciplinares, é algo que envolve complexidade quando pretende-se construir uma rede de conhecimentos, no entanto, por outro lado, é acreditar na promoção de diversos efeitos, por exemplo: provocar inquietações diante das práticas de ensino em Geografia; entender que a partir da forma relacional entre professor e aluno surgem diversos indicativos na prática que devem ser repensados; despertar para novos caminhos epistemológicos e permitir-se à mudanças diante da percepção do mundo. De modo em que, estes efeitos são apenas alguns notes possível diante do processo de problematização das práticas pedagógicas no ensino de Geografia e do processo de aprendizagem professor-aluno.

Um grande desafio da educação são formações continuadas e especificas para o professor de Geografia, especificamente, do ensino fundamental; fazendo construir uma percepção contemporânea diante do processo cultural mundial e local; a cultura que a escola está inserida; a cultura deste professor (pensamentos ideológicos e comportamentais) e a cultural do aluno (pensamentos não sistematizados, clareza deficiente de conceitos básicos e comportamentos da cultural global tecnológica, que o faz si sentir indiferente ao espaço escolar) - todos estes aspectos culturais devendo ser entendidos no princípio da interconectividade de saberes. Dando um amplo sentido a relação aluno-escola-professor, sem hierarquia de ordem.

A essência da formação continuada docente não está como um foco central e único no cumprimento formal estabelecido pela Lei de Diretrizes e Bases. Ela ultrapassa os parâmetros 
legais, pois "formar professores com qualidade social e compromisso político de transformação educacional tem se mostrado um grande desafio ás pessoas que compreendem a educação como um bem universal, [...] como um direito humano e social na formação da cidadania". (FELDMANN, 2009, p.71).

Como um exemplo, informou-se na Secretária de Educação do Município de Salgueiro, Pernambuco, de alguns dados sobre formação continuada, particularmente para os professores formados em Geografia dentro do víeis dito anteriormente, e segundo a Diretora de Ensino da Secretária Municipal de Salgueiro (2015) os professores possuem formação continuada mensalmente voltada para conscientização de pertencimento escolar. Para a Diretora os professores, principalmente, do ensino fundamental II não conseguem transpor as dificuldades dos alunos nos aspectos comportamentais e de conhecimento sistemático. Conforme ela, os professores deste ciclo, acreditam que os alunos já deviam vir do ensino fundamental I “educados”.

A própria secretária é a promotora do programa de formação continuada e visa dirimir esta problemática com formação continua de conscientização. Só na rede de educação do município de Salgueiro existem 300 professores polivalentes, atuantes em sala de aula. Já os que trabalham com a disciplina, especificamente, de Geografia são 10 professores. (DIRETORA DE ENSINO, 2015).

Outro problema e o maior de todos, conforme a Diretora (2015) é os professores não saberem como lhe dar com o aluno que vive no contexto global do mundo da informação, em que espaço e tempo são praticamente simultâneos. Problemática, que se sabe ser pertinente, no meio escolar e passa diretamente a interferir no processo de ensino-aprendizagem.

Para Feldmann (2009, p.73), “[...] a formação de professores é perspectivada a partir do fazer docente no contexto social, político e cultural [...]", mostrando que toda conjuntura destas dimensões é influenciável no ato de ensinar, portanto, as transformações no cenário global no que diz respeito a tecnologia, mudanças socioeconômicas, políticas e transformações ambientais exercem efeito direto nas ideologias educacionais definidas pelos docentes. O que o mundo pensa interfere diretamente no ensino e aprendizagem.

As mudanças sociais no século XX, como a atual Revolução Técnica Científica Informacional transformaram o ato de pensar e agir da sociedade contemporânea - a sociedade tecnológica - conectada ao mundo da informação, em que está conectado não é mais um privilegio da classe elitista, embora esta classe, manipule a sociedade. (SANTOS, 2006). Para Feldmann (2009) a sociedade da informação conduzida pelas transformações mundiais, interferem sobretudo, o universo escolar. E, Santos (1982) coloca que a Geografia pode ser a ciência que levará o sujeito a pensar seu espaço de modo a ter mecanismos para transformar sua realidade. 
Desse modo, a relação professor e aluno são afetadas por existir um confronto de realidades de vida e de formação muitas vezes extremamente opostas. Feldmann (2009) e Cavalcanti (1998) são convergentes em dizerem que a formação acadêmica dos professores de Geografia possui uma desvinculação entre a teoria e a prática. De que, a abordagem dos conceitos e a suas definições, bem como, não trabalhar com a sua complexidade e interdisciplinaridade é um dos fatores de base que mais promove obstáculos na concretização de uma prática pedagógica, somado ao agravante da "constatação das deficiências [...] e ausências de formação continuada sistemática [...]". (CAVALCANTI, 1998, p.169)

A sociedade contemporânea transforma-se rapidamente por meio de novos costumes, ou melhor, de consumo e tecnologia, de reprodução espacial e mutações na paisagem, de organização e imposição do poder territorial, exploração da natureza e violência contra a humanidade de todas as ordens socioculturais. Esta mesma sociedade exige respostas vindas do nicho educacional, portanto, segundo Feldmann (2009, p.74): “quais são as exigências desta sociedade contemporânea para o professor da escola brasileira e como pensar esta formação? Para ele:

Pensar a formação dos professores é sempre pensar a formação do humano e, nessa perspectiva, se vislumbra a construção de mudanças em qualquer que seja o seu espaço de ação. Mudança entendida como aprimoramento da condição humana, como liberdade de expressão e comunicação e como o desenho de possibilidades de um mundo melhor, de uma melhor convivência entre as pessoas. (FELDMANN, 2009, p.78)

$\mathrm{O}$ ato de promover a formação continuada para o professor associa-se em contribuir na visão humanitária diante do aluno, assim, nutrindo a formação de sua cidadania. Um momento de movimento humanitário em que ambos, professor e aluno, se reconhecem como sujeitos ativos e passivos. Ou, como descreve Tardif (2005, p.31): "todo trabalho humano sobre e com os seres humanos faz retornar sobre si a humanidade de seu objeto". A relação de intersubjetividade se concretiza quando professor e aluno encontram um ponto de linguagem compreensíveis entre si e isto produz transformação no ensino-aprendizagem e cotidiano de ambos.

Perceber o aluno é compreender o seu espaço vivido e a Geografia enquanto disciplina escolar possui oportunidade de estabelecer relação intrínseca com a reflexão do espaço físico, social e cultural do aluno para que este encontre sentido em sua espacialidade. "Na Geografia, o comportamento pragmático dos alunos deve ser trabalhado com temas que exijam reflexões direcionadas para práticas, tanto na escola local quanto global" (CASTROGIOVANNI, 2007, p.45).

Muitos temas geográficos e seus conceitos devem ser trabalhados de forma interdisciplinar, pois, se acredita que além de ser um requisito interativo, a interdisciplinaridade proporciona uma 
visão completa e densa de um determinado objeto de estudo sem descaracterizar ou descentralizar a ciência deste objeto.

A interdisciplinaridade [...] é definida como regime de cooperação que se realiza entre disciplinas diversas ou entre setores heterogêneos de uma mesma ciência, que se faz por meio de trocas e visando o enriquecimento mútuo. Surge como uma crítica a uma educação fragmentada e encastelada no interior da escola, reprodutora de tradições e opostas às práticas inovadoras. (SANTOS, 2006).

Tanto a escola como o ensino dar-se como necessário tornar atrativo em frente ao aluno da sociedade da informação - um aluno com acesso às informações, com síndromes do pensamento acelerado e constantemente interconectado ao mundo virtual - um mundo das transformações céleres nas categorias espaço e tempo, ou melhor pontuando, da simultaneidade destas categorias. A cada dia surge dificuldade em criar, recriar e interagir com dinamismo e atratividade nas práticas pedagógicas e é o processo que mais se requer uma didática estimulante.

Esse contexto, apresenta a importância de fazer do ato reflexivo das práticas de ensino em Geografia uma constante ação para que se abram a possibilidade e práticas interdisciplinares. Dessa maneira se terá mais espaços de conhecimentos inclusivos e com sentido. Pois, este espaço de são capazes de "superar a fragmentação do conhecimento e para tanto necessita de uma visão de conjunto para que se estabeleça coerência e articulação dos conhecimentos" (LÜCK, 1994, p.60). Ou de outro modo, como abordado por Santos (2006, p. 21) a interdisciplinaridade:

\footnotetext{
Trata-se, portanto, de uma relação entre subjetividade que, do ponto de vista epistemológico e pedagógico, promove uma mudança de atitude do pesquisador, do professor, do aluno perante o problema a saber, substituindo uma concepção fragmentária por outra, unitária do conhecimento e do ser humano. Esta intersubjetividade das trocas entre os envolvidos num processo de pesquisa ou de ensino e aprendizagem e pela integração das disciplinas num mesmo processo que tem uma clara intencionalidade: a busca do saber unificado $[\ldots]$
}

Em busca do saber unificado que o professor de qualquer ciência deveria se propõe desenvolver nas suas atividades práticas, sejam em formas de oficinas, leituras de livros ou imagens, filmes, exercícios, enfim, nas inúmeras maneiras de envolver os alunos; uma vez que a interdisciplinaridade representa o encontro de outros conhecimentos "ela não se ensina, nem se aprende: vive-se, exerce-se" (FAZENDA, 1996, p.109). Além disso, constrói-se uma complexidade de conceitos articulados em uma rede mental capaz de expandir e dar sentido ao que se aprende.

\section{Metodologia}

A hipótese deste trabalho desvela-se em que refletindo as práticas pedagógicas no ensino de Geografia cria-se a oportunidade de autoanalise sobre a construção epistemológica e filosófica desta ciência, e afirmar que no decorrer do processo histórico e cultural ela se internalizou no ensino e se 
materializou na didática do professor, com isto, promove o processo de ser avaliado e resignificado com práticas mais significantes para o mundo vivido, principalmente, do aluno.

Assim, considera-se a pesquisa de natureza qualitativa com base em revisão bibliográfica e uma pequena amostragem de entrevista do tipo conversação informal.

\section{Resultados e Discussão}

A Geografia enquanto ciência possuí a capacidade de propor reflexões e meios interventivos para o espaço vivenciado, fato de ter enquanto objeto de estudo central o espaço geográfico, defendido por muitos Geógrafos da linha humanista e crítica, como Santos (1982), Moraes (1994), Carlos (2011), entre outros, como um produto que se materializa somente nas relações sociais, pois estas produzem seus desejos de materialidade e dão formas e sentidos ao uso deles específicos a temporalidade em que estão. Cria-se com isto a complexidade relacional entre espaço, materialidade e tempo dentro de uma rede de dimensões culturais, econômicas, ambientais e políticas.

Esta compreensão sobre a composição espacial e dinâmica relacional da sociedade no meio ambiente em que se insere trata-se do mundo do aluno que se depara com a Geografia enquanto disciplina escolar "ainda desinteressante", um fato concreto quando se analise o ensino de Geografia, principalmente, nas séries iniciais. Se a Geografia é capaz de analise os conflitos territoriais, sócias, étnicos e religiosos do mundo não só contemporâneo; se a Geografia é capaz de trazer discussões efervescentes sobre a revolução técnica científica informacional e globalização como apontou Milton Santos (1983); se a Geografia possui ferramentas decifradoras das estratégias do território falada por Roberto Lobato (1999), porquê o professor de Geografia não sabe entender o mundo atual que o aluno está inserido?

Certamente, o processo depreciativo pelo ensino de Geografia é parte de uma rede tanto científica, de formação acadêmica e estrutural da própria educação verbera diretamente no mundo do aluno. Como disse Santos (2006), a educação é fragmentada e dissociada do mundo real. Desse modo, caberá ao professor fazer o elo perdido entre o conhecimento e o sentido de obtê-lo e praticálo. Vissentini (1985) escreveu um artigo cujo título foi "Para onde vai o ensino de Geografia" e este já nos remete a interconectividade com o elemento coadjuvante intermediador deste processo, o professor.

Feldmann (2009) disse que a formação do professor é, sobretudo, uma formação humana, portanto, ocorreram mudanças interiores pessoais e no ambiente em que está pela razão do conhecimento produzir liberdade e autonomia. Mas, porque o ensino, particularmente, de Geografia encontra-se deficitário na construção crítica e (des)alienadora do aluno? Seria apenas uma questão de formação continuada, políticas públicas educacionais que valorizasse a categoria? Pacificação de 
alunos imperativos, fim da revolução técnica cientifica informacional tão presente no cotidiano da sala de aula, por exemplo, o uso de celulares no momento da aula? Claro que não. Estes são fatores que aumentam a temperatura do desanimo para quem ensina e aprende Geografia, porém, o ponto crucial de como está a Geografia no âmbito escolar atual é parte da construção epistemológica, tendências pedagógicas e metodológicas escolhidas e das práticas de ensino, todas, formadas desde a historicidade desta ciência que por muitas vezes se omitiu diante da oportunidade de desvelar a dominação de territórios e nações.

Por outro lado, os autores apontaram uma esperança de que é possível vivenciar a Geografia dos sentidos, no momento em que ela é interconectada ao mundo real revelando, praticando e problematizando o cotidiano. Está é a Geografia que traz sentido ao espaço vivido do aluno, pois ele poderá se ver como um sujeito geográfico que produz, reproduz, reivindica o seu espaço ao mesmo tempo e que o vive com consciência sócio espacial.

Autores como Morin (2009), Castrogiovanni (2007), Santos (2006) e Fazenda (1979) apresentaram a interdisciplinaridade como um elo de discussão e práticas subjetivas que permite uma determinada ciência dialogar com outras sem perder o foco do seu objeto de estudo. São intersubjetivas entre ciências capazes de abranger e ganhar outras dimensões de sentido. Portanto, é pertinente citar o que Morin (2009) falou acerca do pensamento complexo. Conforme este autor, o pensamento complexo não é aquele intangível, ilegível, impenetrável, incompreensível e sim aquele que é percebido e entendido na interconexão de saberes. Apenas assim o conhecimento adquire sentido porque faz parte de uma rede conceitual, levando a crer na potencialidade de abordagens interdisciplinares que a Geografia enquanto ciência e disciplina escolar possuí. Relembrando Castrogiovanni (2007, p.44): “A Geografia talvez seja a disciplina que mais trabalhe com práticas interdisciplinares, percorrendo um leque de possibilidades na área de educação". Desse modo, ampliando a formação cidadã do sujeito discente.

\section{Conclusões}

A Geografia revela-se uma disciplina escolar que precisa transpor de desinteressante à interessante por meio da didática do professor que por sua vez precisa auto avaliar suas práticas, apesar da academia ter criado uma Geografia dicotômica entre pesquisa e disciplina escolar.

Apresentaram os autores que a prática da interdisciplinaridade é um caminho amplo, consistente e intersubjetivo que ajudará o aluno a problematizar o meio do qual se insere trazendo sentido as suas experiências. Logo, acreditasse que apesar da conjuntura política, estrutural e cultural da educação que está envolvido o ensino de Geografia existem possibilidade de ocorrer o 
processo inverso indicado inicialmente; sem esquecer que as tendências pedagógicas e metodológicas do ensino de Geografia são produtos de um processo ideológico, sobretudo.

\section{Referências}

CARLOS. Ana Fani Alessandri. Da "organização" à "produção" do espaço no movimento do pensamento geográfico. In: ; SOUZA, Marcelo Lopes de; Sposito, Maria Encarnação Beltrão (orgs.). A Produção do espaço urbano: agentes e processos, escalas e desafios. São Paulo: Contexto, 2011.

CASTROGIOVANNI, Antonio Carlos. Para entender a necessidade de práticas prazerosas no ensino de geografia na pós-modernidade. In: CASTROGIOVANNI, Antônio Carlos; KAERCHER, Nestor André; REGO, Nelson. Geografia: práticas pedagógicas para o ensino médio. Porto Alegre: Artmed, 2007.

CAVAlCANTI, L. de S. Geografia, Escola e Construção de Conhecimentos. Campinas - Sp: Papirus, 1998.

DIRETORA DE ENSINO DA SECRETÁRIA MUNICIPAL DE SALGUEIRO-PE. Entrevista conversação informal. 15 de jun de 2015 .

FAZENDA, Ivani Catarina Arantes (Org.). Integração e interdisciplinaridade no ensino brasileiro: efetividade ou ideologia? São Paulo: Loyola, 1979.

FELDMANN, M. G. Formação de professores e cotidiano escolar. In: Formação de professores e escola na contemporaneidade. São Paulo: Editora Senac, 2009; p. 79, 80

LUCK, H. Pedagogia interdisciplinar: fundamentos teórico-metodológicos. Petrópolis: Vozes, 1994.

SANTOS, Eloísa Helena. A interdisciplinaridade como eixo articulador do Ensino Médio e do Ensino Técnico de nível Médio Integrados. In: Ensino Médio integrado à educação profissional: integrar para quê? Brasília: Ministério da Educação, Secretaria de Educação Básica, 2006.

SANTOS, M. Pensando o espaço do homem. São Paulo: Hucitec, 1982.

MORAES, Ant. Carlos Robert. Geografia: Pequena Historia Critica. São Paulo: Hucitec, 1994.

MORIN, Edgar. Educação e complexidade: os sete saberes e outros ensaios. 4 ed. - São Paulo: Cortez: 2009.

TARDIF. Maurice. Saberes docentes e formação profissional. Petrópolis: Vozes, 2005.

VESENTINI, J.W. Geografia Crítica e Ensino. Orientação. São Paulo. N.6. p.53-58.1985 